\title{
Effects of Salt and Water Stress on Plant Growth and on Accumulation of Osmolytes and Antioxidant Compounds in Cherry Tomato
}

\author{
Mohamad AL HASSAN ${ }^{1}$, Marina MARTÍNEZ FUERTES ${ }^{1}$, Francisco José RAMOS \\ SÁNCHEZ ${ }^{1}$, Oscar VICENTE ${ }^{1 *}$, Monica BOSCAIU² \\ ${ }^{1}$ Universitat Politécnica de València, Instituto de Biología Moleculary Celular de Plantas (UPV-CSIC), CPI, edificio 8E, Camino de Vera s/n, 46022 \\ Valencia,Spain; ovicente@ibmcp.upv.es (*orrespondingauthor) \\ ${ }^{2}$ Universitat Politècnica de València, Instituto Agroforestal Mediterráneo (UPV), CPI, edificio 8E, Camino de Vera s/n, 46022 Valencia, Spain
}

\begin{abstract}
The effects of salt and water stress on growth and several stress markers were investigated in cherry tomato plants. Some growth parameters (stem length and number of leaves) and chlorophyll contents were determined every third day during plant growth, and leaf material was collected after 25 and 33 days of treatment. Both stresses inhibited plant growth; chlorophyll levels, however, decreased only in response to high $\mathrm{NaCl}$ concentrations. Proline contents largely increased in leaves of stressed plants, reaching levels high enough to play a major role in cellular osmotic adjustment. Despite reports indicating that tomato does not synthesize glycine betaine, the stress-induced accumulation of this osmolyte was detected in cherry tomato, albeit at lower concentration than that of proline. Therefore, it appears that the plants are able to synthesise glycine betaine as a secondary osmolyte under strong stress conditions. Total sugars levels, on the contrary, decreased in stress-treated plants. Both stress treatments caused secondary oxidative stress in the plants, as indicated by a significant increase in malondialdehyde (MDA) contents. Water stress led to an increase in total phenolics and flavonoid contents and a reduction of carotenoid levels in the leaves; flavonoids also increased under high salinity conditions.
\end{abstract}

Keywords: proline, glycine betaine, carbohydrates, MDA, carotenoids, phenolics, flavonoids

\section{Introduction}

Tomato is grown in a wide range of climatic conditions, from the tropics to subarctic regions, but its optimal cultivation areas are found in warm and rather dry regions, such as Mediterranean countries (Cuartero and Fernández Muñoz, 1999). In these arid or semi-arid zones, water stress and high soil salinity are common environmental factors that can significantly reduce crop yields. One of the most general responses to drought and salinity - as well as to other abiotic stress conditions, also causing cellular dehydration in plants, such as cold, elevated temperatures or exposure to heavy metals - is based on the synthesis and cytoplasmic accumulation of osmolytes, a conserved phenomenon observed in all plants, tolerant as well as sensitive to stress (Munns and Tester, 2008; Parida and Das, 2005; Parvaiz and Satyawati, 2008). Osmolytes are 'compatible solutes', very soluble, low-molecular-weight organic compounds that do not interfere with normal metabolism even when present at high concentrations. While toxic inorganic ions are sequestered in vacuoles, organic osmolytes accumulate predominantly in the cytoplasm, preventing or limiting cellular dehydration (Büssis and Heineke, 1998; Handa et al.,
1986; Stewart and Lee, 1974). Reduction of the osmotic potential due to accumulation of osmolytes in response to stress improves the ability of the plant cells to maintain turgor pressure at low water potentials, which is essential for biological processes such as photosynthesis or cell expansion, as well as for maintaining enzymatic activities (Tyree and Jarvis, 1982). Besides their role in osmotic adjustment, osmolytes act as osmoprotective substances, directly stabilising proteins and cell membranes under dehydration conditions. Osmolytes also protect cells from oxidative stress by inactivating 'reactive oxygen species' (ROS) (Hare et al., 1998; Szabados and Savouré, 2010).

The amino acid proline (Pro) and glycine betaine (GB), a quaternary amine, are probably the most common compatible solutes synthesised by plants as a response to abiotic stress (Ashraf and Foolad, 2007; Chen and Murata, 2008; Verbruggen and Hermans, 2008). As for other osmolytes, besides their role in osmoregulation, both compounds can act as 'low-molecular-weight chaperons', contributing to maintain the active conformation of macromolecules in stressed plants, and participate in detoxification of ROS. Moreover, Pro and GB seem to be 
involved, directly or indirectly, in the regulation of gene expression as signalling molecules, and also serve as metabolites for the cellular storage of carbon and nitrogen during stress, which would be used by the cell once stress has ceased (Munns and Tester, 2008; Szabados and Savouré, 2010). Compatible solutes also include soluble carbohydrates, such as sugars (e.g. sucrose, glucose, fructose or trehalose), sugar alcohols (sorbitol, mannitol, as well as different inositol isomers and derivatives), and the raffinose family of oligosaccharides (Gavaghan et al., 2011; Parida et al., 2002). Although sugars have been shown to act as functional osmolytes in several species, it is not so easy to assess their specific functions in the responses to stress, which can be masked by their multiple additional roles as direct products of photosynthesis, components of the primary metabolism and regulatory molecules (Gil et al., 2013).

A secondary effect of abiotic stresses, including drought and salinity, is the increased generation of 'reactive oxygen species' (ROS), including highly reactive free radicals such as superoxide, singlet oxygen, hydroxyl or perhydroxyl radicals, as well as hydrogen peroxide, molecular oxygen, ozone and other strong oxidant molecules (Apel and Hirt, 2004). ROS are continuously generated by plants as by-products of different metabolic pathways, but under stress their production increases leading to oxidative damage of cellular membranes, proteins, carbohydrates and DNA (Van Breusegem and Dat, 2006). In response to stress, plants activate powerful antioxidant systems, both enzymatic (e.g., superoxide dismutase, catalase, glutathione reductase, several peroxidades) and non-enzymatic (vitamins $\mathrm{C}$ and $\mathrm{E}$, carotenoids, flavonoids and other phenolic compounds etc.) (Apel and Hirt, 2004).

Carotenoids are pigments with several functions in plants, besides their direct role in photosynthesis, including their involvement in the mechanisms of oxidative stress tolerance (Gill and Tuteja, 2010). Phenolic compounds also fulfil multiple roles in plants, as structural components of cell walls, participating in the regulation of growth and developmental processes, as well as in the mechanisms of defence against herbivores and pathogens; in addition, they are involved in the responses of plants to practically all types of abiotic stress: UV radiation, extreme temperatures, mineral nutrient imbalance, drought, salinity, heavy metals and herbicides among others (Cheynier et al., 2013; Gould and Lister, 2006). Flavonoids represent the main and most complex subgroup of polyphenols, including more than 9,000 different compounds with a wide array of biological functions (Di Ferdinando et al., 2012; Pollastri and Tattini, 2011; Treutter, 2005, 2006; Winkel-Shirley, 2002). In the last decade, they have been the object of many studies, not only due to the academic interest in elucidating their multiple functions in plants, but also because their alleged beneficial effects for human health, as powerful dietary antioxidants (Wiseman, 2006).

Responses to salinity in tomato, within its salt-tolerance range under natural conditions, have been extensively studied, but only few authors have analysed its responses to higher salt concentrations (Maggio et al., 2004). Subjecting the plants to 'shock treatments' at very high $\mathrm{NaCl}$ concentrations, well above those they encounter in the field, may trigger adaptation mechanisms that cannot be observed at low or moderate salinity levels. In addition, there are only a few papers reporting the effects of both salinity and drought on the same plant material (Giannakoula and Ilias, 2013). These two adverse environmental conditions, which will worsen as a consequence of climate change, could seriously affect tomato production in Mediterranean countries in the coming years.

The aims of the present study were to analyse the effects on the growth of tomato plants of water and salt stress treatments, applied under different conditions, including high $\mathrm{NaCl}$ concentrations beyond the tolerance threshold, to allow detection of time- and salt concentration- dependent effects. These growth responses were correlated with accumulation of several biochemical stress markers, associated to general mechanisms of abiotic stress tolerance: the main osmolytes (proline, glycine betaine and total soluble sugars), responsible for cellular osmotic adjustment; malondialdehyde (MDA), as a marker of oxidative stress; and some nonenzymatic antioxidants (total carotenoids, phenolics and flavonoids), synthesised in response to secondary oxidative stress. The experiments were carried out in cherry tomato, a variety that has not been extensively studied despite its growing commercial interest.

\section{Materials and methods}

\section{Plantmaterial}

Cherry tomato (Solanum lycopersicum L. var. cerasiforme) is clearly differentiated from other tomatoes by the smaller size of its fruits. Plants of this variety are vigorous in their growth and have a higher leaves/fruits ratio; therefore, the fruits receive more photoassimilates, in comparison to larger-size varieties, and have higher sugar and acid contents. Thus, cherry tomatoes are more flavoured and are used mostly for fresh consumption. Seeds of cherry tomato were kindly provided by Pilar Corella, from Rijk Zwaan Ibérica S.A. (Almería, Spain).

\section{Plantgrowth}

The seeds were sown in seed trays containing a mixture of commercial peat and vermiculite (1:1) and were placed in a greenhouse with regulated temperatures ranging between 17 and $23^{\circ} \mathrm{C}$, under a long-day photoperiod ( $16 \mathrm{~h} \mathrm{light} \mathrm{/} 8 \mathrm{~h}$ dark). Young plants were transferred to individual pots (11 cm in diameter) on the same substrate 36 days after sowing and were watered for 26 additional days with a standard nutritive solution. Then, salt and water stress treatments started, by watering the plants with increasing $\mathrm{NaCl}$ concentrations $(150,300$ and $450 \mathrm{mM} \mathrm{NaCl}$ in nutritive solution) and by stopping irrigation altogether, respectively; 10 plants were used per treatment. Watering was carried out twice a week by adding $1.5 \mathrm{~L}$ of the salt solutions to each tray, which contained 12 standard pots. Control plants were grown in parallel, maintaining the standard irrigation regime with nutritive solution. After starting the treatments, plant height was measured and the number of leaves per plant was counted every three days, to assess the effect of stress on vegetative plant growth. Chlorophyll content was also determined at the same times, using a portable 'Chlorophyll meter' SPAD-502Plus (Konica Minolta).

For each stress treatment, including non-treated controls, leaves in equivalent positions were detached from all plants, 25 and 33 days after starting the treatments, and weighed on a precision balance to calculate the average leaf fresh weight (FW) corresponding to each treatment. Part of the leaf material was stored at $-75^{\circ} \mathrm{C}$ until further use, and part was dried at $65^{\circ} \mathrm{C}$ until constant weight, to measure the average leaf dry weight (DW) for 
each treatment. Average leaf 'water content' after each treatment, expressed in percentage, was calculated as $[(\mathrm{FW}-\mathrm{DW}) / \mathrm{FW}] \mathrm{x}$ 100.

\section{Electric conductivity of the substrate}

Soil EC $\mathrm{E}_{1: 5}$ was checked at the beginning and at the end of the treatments. Soil samples were taken from three pots per treatment, air-dried and then passed through a 2-mm sieve.

A soil:water (1:5) suspension was prepared in Milli Q water and stirred for one hour at $600 \mathrm{u} / \mathrm{min}$ at $21{ }^{\circ} \mathrm{C}$. Electric conductivity was measured with a Crison Conductivity meter 522 and expressed in $\mathrm{d} S / \mathrm{m}$.

\section{Osmolyte contents}

Pro contents were determined according to the method of Bates et al. (1973) with minor modifications (Vicente et al., 2004). Frozen plant material $(100 \mathrm{mg})$ was ground to a fine powder in a mortar, in the presence of liquid nitrogen. Extraction was carried out with $3 \%$ sulfosalicylic acid and cell debris was removed by filtration. One volume of the filtrate was mixed first with one volume of freshly prepared acid ninhydrin $(25 \mathrm{mg} / \mathrm{mL}$ ninhydrin in 10.44 $\mathrm{M}$ acetic acid and $2.4 \mathrm{M}$ phosphoric acid); then one volume of glacial acetic acid was added, the sample was mixed and incubated at $95^{\circ} \mathrm{C}$ for $1 \mathrm{~h}$. After stopping the reaction by cooling the samples on ice, they were extracted with two volumes of toluene. The absorbance of the organic phase was determined at $520 \mathrm{~nm}$, using toluene as a blank. A calibration curve was obtained for each assay, using solutions of Pro in 3\% sulfosalicylic acid of known, increasing concentrations and subjected to the same treatment as the samples. Pro contents in the plant samples were expressed as ' $u$ mol Pro per gram of dry weight'.

The extraction and quantification of glycine betaine was performed following the method of Grieve and Grattan (1983) with the modifications proposed by Nawaz and Ashraf (2010). Frozen plant material $(100 \mathrm{mg})$ was ground, using a homogenizer (Ultraturrax) in a volume of $2 \mathrm{~mL}$ Milli-Q water and centrifuged for 10 minutes at $-4^{\circ} \mathrm{C}$ and $13,000 \mathrm{rpm}$. One $\mathrm{mL}$ was removed from the supernatant of each extract and mixed with $400 \mu \mathrm{L} \mathrm{HCl}$ $2 \mathrm{~N}$. After stirring, $200 \mu \mathrm{L}$ of each tube was mixed with $80 \mu \mathrm{L}$ of potassium iodide and brought to $100 \mathrm{~mL}$ with Milli-Q water. The tubes were quickly placed in ice and stirred every 20 seconds for 15 $\mathrm{min}$. After $90 \mathrm{~min}, 800 \mu \mathrm{L}$ of cold Milli-Q water and $4 \mathrm{~mL}$ of $1.2-$ dichloroethane - kept in the $-20^{\circ} \mathrm{C}$ freezer until used - were added to each tube. The samples were vortexed for one minute and allowed to settle until the water and the organic phases separated; finally, $1 \mathrm{~mL}$ of the lower aqueous phase was aspirated and its absorbance at $265 \mathrm{~nm}$ was measured in a spectrophotometer. A standard curve was obtained for each assay, using glycine betaine solutions in Milli-Q water of increasing concentration subjected to the same treatment as the plant samples. Glycine betaine contents in the plant samples were expressed as ' $\mu \mathrm{mol}$ GB per gram of dry weight'.

Total sugars were quantified according to the method described by Dubois et al. (1956). Dried material (0.1 g) was crushed and diluted with $3 \mathrm{~mL}$ of $80 \%$ methanol, left on an agitator for $20-48 \mathrm{~h}$ and then mixed with concentrated sulfuric acid and 5\% phenol; finally, absorbance of the samples at $490 \mathrm{~nm}$ was measured in a spectrophotometer. Glucose solutions were used as standard and the amount of total soluble sugars in each sample was calculated as 'mg. equivalent of glucose per gram of dry weight'.
Malondialdehyde and non-enzymatic antioxidants

Malondialdehyde (MDA), total phenolics and flavonoids contents were measured in the same extracts used for total soluble sugars determination ( $0.1 \mathrm{~g}$ of dried material in $3 \mathrm{~mL}$ of $80 \%$ methanol). MDA, a product of membrane lipid peroxidation, is considered as an excellent marker of oxidative stress (Del Rio et al., 2005) and is routinely used to assess the degree of oxidative damage induced in plants by different types of stress (e.g. Aghaleh et al., 2009; Li et al., 2010). MDA content was determined by the thiobarbituric acid-reactive-substances (TBARS) assay, modified to correct for the presence of interfering compounds, as described by Hodges et al. (1999).

Total phenolic compounds were quantified by reaction with the Folin-Ciocalteu reagent, according to Blainski et al. (2013). Absorbance was measured at $765 \mathrm{~nm}$ and the results expressed in equivalents of gallic acid (mg eq. GA g $\mathrm{g}^{-1} \mathrm{DW}$ ), used as standard. Flavonoid contents were determined following the method described by Zhishen et al. (1999); the absorbance was measured at $510 \mathrm{~nm}$, and the amount of flavonoids was expressed in equivalents of catechin (mgeq. $\mathrm{Cg}^{-1} \mathrm{DW}$ ), used as standard.

Total carotenoids were measured and quantified following Sims and Gamon (2002): $0.2 \mathrm{~g}$ fresh material was crushed and diluted in $80 \%$ ice-cold acetone/Tris buffer for 1 hour on a shaker at $4{ }^{\circ} \mathrm{C}$, then centrifuged for $15 \mathrm{~min}$ at $3,000 \mathrm{x}$. The supernatant was separated and optical density was measured at $663 \mathrm{~nm}, 646 \mathrm{~nm}$ and $470 \mathrm{~nm}$ in disposable plastic cuvettes. Total carotenoids values were then converted into $\mathrm{gg} \mathrm{g}^{-1} \mathrm{DW}$.

\section{Statistic analysis}

Data were analysed using the SPSS programme for Windows, v.16.00. Prior to the analysis, the Levene test was applied to check the ANOVA requirements. The significance of differences between treatments was assessed using one-way ANOVA, at 95\% confidence level. The post-hoc Tukey test was used to estimate homogeneous groups when more than two samples were compared.

\section{Results}

\section{Substrate electric conductivity}

The electric conductivity $\left(\mathrm{EC}_{1: 5}\right)$ of the plants' substrate was determined before and after the stress treatments (Table 1). In the control pots, not treated with $\mathrm{NaCl}$, the $\mathrm{EC}_{1: 5}$ value at the end of the experiment was significantly higher than the initial one; this can be easily explained by accumulation of ions present in the nutritive solution. As expected, $\mathrm{EC}_{1: 5}$ increased even more after watering the plants with $\mathrm{NaCl}$ solutions of increasing concentration, in a concentration-dependent manner. The mean $\mathrm{EC}_{1: 5}$ also increased slightly in the substrate of water stressed plants, as compared to the initial value - most likely due to concentration of ions from the nutritive solution - but the difference was not statistically significant.

\section{Stress-induced inbibition of plant growth}

Both salt and water stress negatively affected vegetative plant growth, which was estimated by the increase in plant length and in the number of leaves during the 33 days of treatment (Fig. 1). As compared to the unstressed controls, all $\mathrm{NaCl}$ concentrations tested totally blocked growth of tomato plants, with a clear concentration effect: the higher the salt concentration used, the shorter the lag period before growth inhibition was observed 
Table 1. Substrate electric conductivity $\mathrm{EC}_{1: 5}(\mathrm{dS} / \mathrm{m})$, measured in soil:water $(1: 5)$ extracts at the beginning $($ day 0$)$ and at the end (day 33$)$ of the salt and water stress treatments

\begin{tabular}{ccccccc}
\hline Treatment & $($ day 0$)$ & $0 \mathrm{mM} \mathrm{NaCl}$ & $150 \mathrm{mM} \mathrm{NaCl}$ & $300 \mathrm{mM} \mathrm{NaCl}$ & $450 \mathrm{mM} \mathrm{NaCl}$ & Water Stress \\
\hline $\mathrm{EC}_{1: 5}$ & $0.21 \pm 0.05 \mathrm{a}$ & $0.94 \pm 0.08 \mathrm{~b}$ & $2.56 \pm 0.39 \mathrm{c}$ & $3.37 \pm 0.35 \mathrm{~d}$ & $4.78 \pm 0.51 \mathrm{e}$ & $0.38 \pm 0.18 \mathrm{a}$ \\
\hline Different lower case letters indicate significant &
\end{tabular}

Table 2. Effects of increasing salt concentration on MDA and non-enzymatic antioxidant levels in plants after 25 days (sampling 1 ) and 33 days (sampling 2) of treatment

\begin{tabular}{|c|c|c|c|c|c|}
\hline \multirow{2}{*}{ Parameters } & \multirow{2}{*}{ Sampling } & \multicolumn{4}{|c|}{ Salt treatments $(\mathrm{mM} \mathrm{NaCl})$} \\
\hline & & 0 & 150 & 300 & 450 \\
\hline MDA & 1 & $145.07 \pm 13.00 \mathrm{a}$ & $163.45 \pm 8.60 \mathrm{ab}$ & $169.03 \pm 10.00 \mathrm{ab}$ & $214.16 \pm 2.90 \mathrm{~b}$ \\
\hline$\left(\mathrm{nmol} \mathrm{g}{ }^{-1} \mathrm{DW}\right)$ & 2 & $149.30 \pm 7.00 \mathrm{a}$ & $188.24 \pm 10.00 \mathrm{~b}$ & $206.02 \pm 4.00 b c$ & $237.56 \pm 20.00 c$ \\
\hline Total carotenoids & 1 & $648.02 \pm 31.00 b$ & $613.48 \pm 31.00 \mathrm{~b}$ & $546.00 \pm 42.00 \mathrm{ab}$ & $344.37 \pm 19.00 \mathrm{a}$ \\
\hline$\left(\mu g^{-1} \mathrm{DW}\right)$ & 2 & $659.53 \pm 36.00 c$ & $473.01 \pm 27.00 b$ & $352.98 \pm 16.00 \mathrm{ab}$ & $306.17 \pm 18.00 \mathrm{a}$ \\
\hline Total phenolics & 1 & $9.71 \pm 0.17 \mathrm{a}$ & $11.64 \pm 1.60 \mathrm{ab}$ & $13.05 \pm 0.90 b$ & $14.70 \pm 0.83 c$ \\
\hline (mg eq. $\mathrm{GA} \mathrm{g}^{-1} \mathrm{DW}$ ) & 2 & $12.41 \pm 0.60 a$ & $17.09 \pm 0.30 \mathrm{~b}$ & $15.85 \pm 3.30 \mathrm{~b}$ & $17.64 \pm 2.20 b$ \\
\hline Total flavonoids & 1 & $10.19 \pm 0.30 \mathrm{a}$ & $11.24 \pm 0.80 \mathrm{~b}$ & $12.24 \pm 1.10 \mathrm{~b}$ & $12.87 \pm 0.50 b$ \\
\hline (mg eq. $\mathrm{C} \mathrm{g}^{-1} \mathrm{DW}$ ) & 2 & $8.74 \pm 0.60 \mathrm{a}$ & $11.03 \pm 1.00 \mathrm{~b}$ & $11.64 \pm 0.50 \mathrm{~b}$ & $13.74 \pm 0.50 c$ \\
\hline
\end{tabular}

Values shown are means followed by \pm SD $(n=5)$. Different lower case letters in a file indicate significant differences between treatments, for each compound and sampling; Abbreviations: MDA, malondialdehyde; GA, gallic acid; C, catechin; DW, dry weight
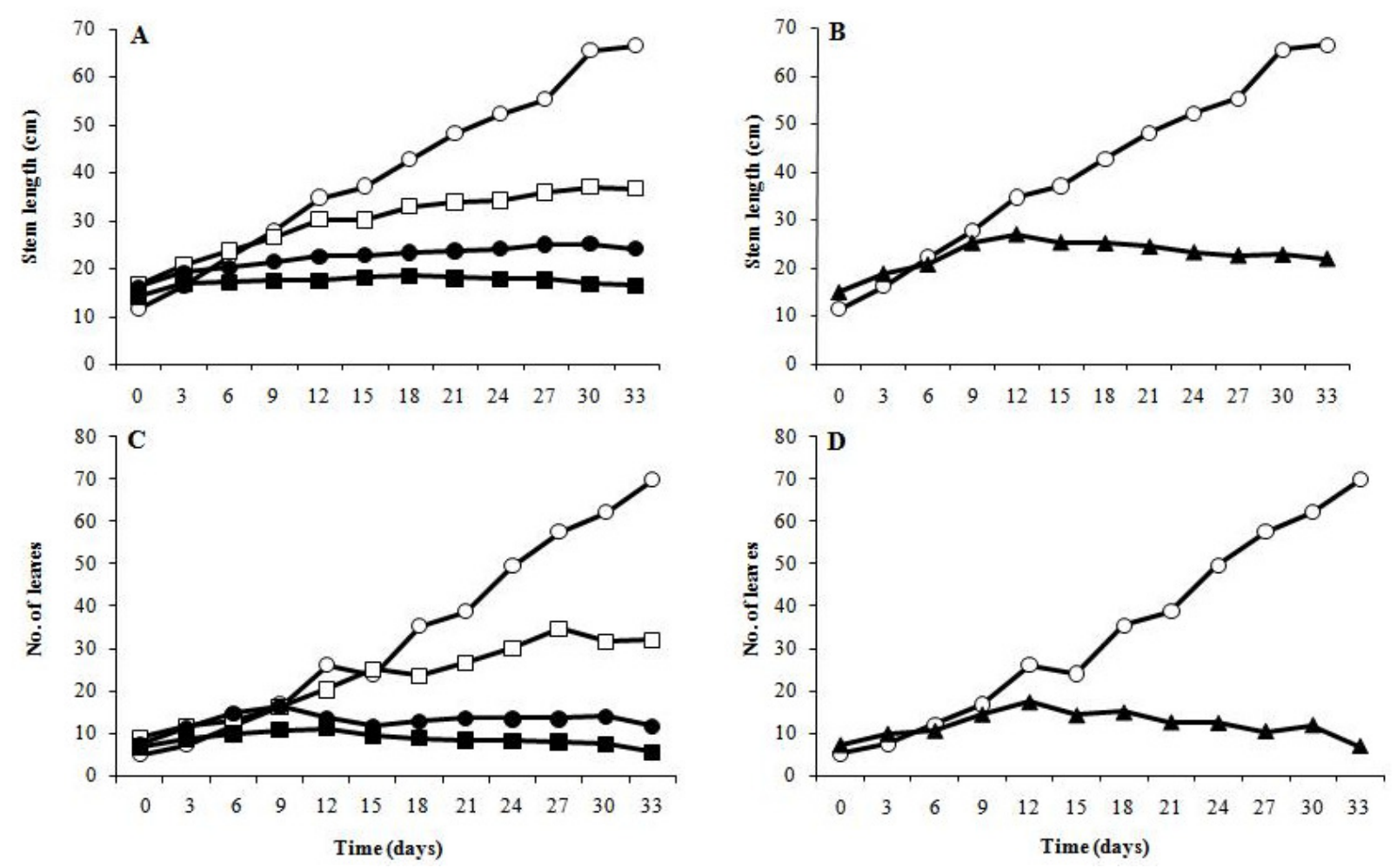

Fig. 1. Mean stem length $(A, B)$ and mean number of leaves $(C, D)$ changes during the salt $(A, C)$ and water $(B, D)$ stress treatments. Control, non-stressed plants (-o-, all panels). $50 \mathrm{mM}(-\square-), 100 \mathrm{mM}(-\bullet-)$ and $150 \mathrm{mM}(-\square-) \mathrm{NaCl}$ (panels A, C). Water-stressed plants (- $\mathbf{A}$-, panels B, D)

(Figs. 1A and C). Water stress also stopped stem growth and the increase in leaf number; this effect was clearly observed 9 days after the last irrigation with nutritive solution, once the substrate had dried (Figs. 1B and D).

Apart from the growth parameters measured continuously, stress-induced inhibition of plant growth was also assessed by determining the mean fresh weight (FW) and dry weight (DW) of the tomato leaves after 25 days (sampling 1 ) and 33 days (sampling 2) of salt or water stress treatment (Fig. 2). A significant concentration-dependent decrease of FW was observed in salt-treated plants, reaching approximately $75 \%$

reduction in those irrigated with $450 \mathrm{mM} \mathrm{NaCl}$, with respect to the non-treated controls. In the presence of this high salt concentration, the plants were already strongly affected after 25 days of treatment and no significant differences were found between the two samplings; at lower salt levels - 150 or $300 \mathrm{mM}$ $\mathrm{NaCl}$ - reduction of FW increased with the duration of the treatment (Fig. 2A). Similar qualitative results were obtained when the plants were submitted to water stress, although with stronger differences between the two samplings: after 25 days without irrigation plant FW was reduced by ca. $25 \%$, as average, but by almost $90 \%$ after 33 days of treatment (Fig. 2B). The 

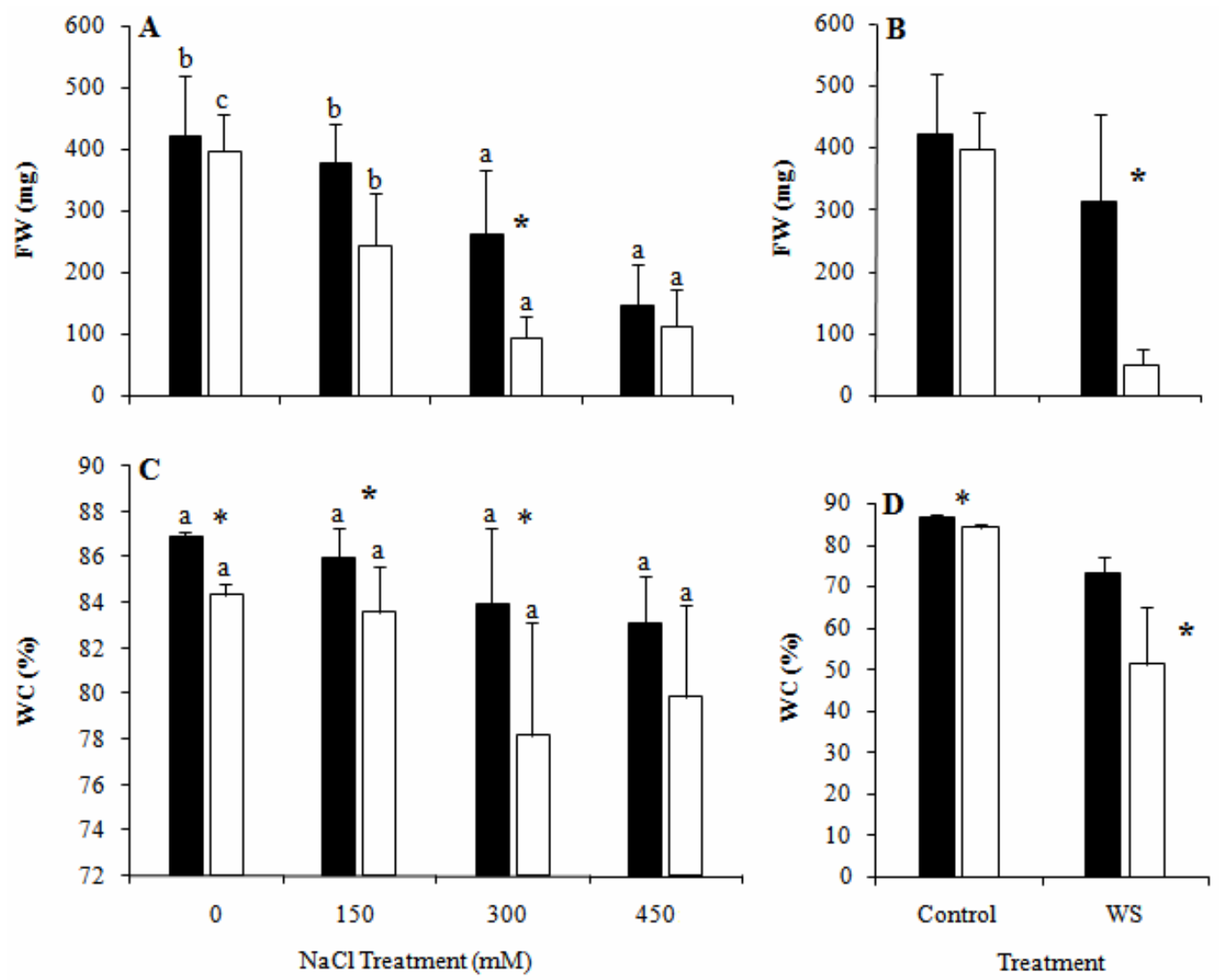

Fig. 2. Average fresh weight (A, B) and relative water content (WC) as percentage of fresh weight (C, D) of tomato leaves after 25 days (sampling 1, black bars) or 33 days (sampling 2, white bars) of salt (A, C) or water (B, D) stress treatments (means \pm SD, $n=3$ ). Different lower case letters indicate significant differences between treatments, for the same sampling, according to Tukey test $(\alpha=0.05)$; asterisks indicate significant differences between sampling 1 and sampling 2 , for each treatment

relative decrease in FW under water stress conditions - as compared with the control plants - was not only a consequence of the inhibition of growth, but also due to a significant loss of water, as shown by the calculated water content of the tomato leaves: it was only $50 \%$ of the FW for the plants maintained for 33 days without water, while for those irrigated normally with nutritive solution water content was about $85 \%$ of the total leaf weight (Fig. 2D). In the presence of salt, a general, but not statistically significant, decrease of the mean leaf water content was observed with increasing $\mathrm{NaCl}$ concentrations, both after 25 and 33 days of treatment, whereas significant differences were detected between the samples collected at different times for each $\mathrm{NaCl}$ concentration, up to $300 \mathrm{mM}$ (Fig. 2C).

\section{Chlorophyll content}

The chlorophyll content of crop plants is positively correlated with their photosynthetic activity (Gummuluru et al., 1989) and a reduction of chlorophyll level contributes to the inhibition of photosynthesis observed under abiotic stress conditions. A decrease in chlorophyll levels with respect to the controls was indeed detected in plants irrigated with high salt concentrations - 300 and $450 \mathrm{mM} \mathrm{NaCl}$ - for two weeks or longer periods (Fig. 3A). On the other hand, no significant differences with non-stressed plants were observed when a moderate $-150 \mathrm{mM}$ - NaCl concentration was used (Fig. 3A) or when the tomato plants were subjected to the water stress treatment (Fig. 3B); this latter observation was consistent with

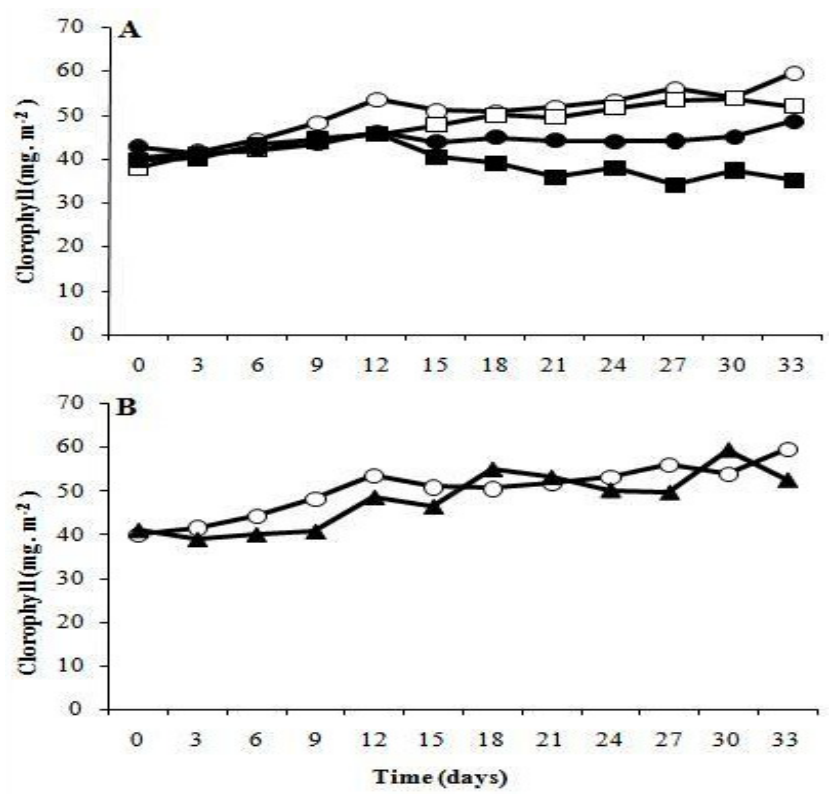

Fig. 3. Mean chlorophyll contents (mg per square meter) measured with a portable chlorophyll meter in leaves of tomato plants during the salt $(\mathrm{A})$ and water $(\mathrm{B})$ stress treatments $(\mathrm{n}=10)$. Control, nonstressed plants (-o-, in both panels). $50 \mathrm{mM}(-\square-), 100 \mathrm{mM}(-\bullet-)$ and $150 \mathrm{mM}(-\boldsymbol{-}) \mathrm{NaCl}$ (panel A). Water-stressed plants (- $\mathbf{\Delta}$-, panel B) 
6
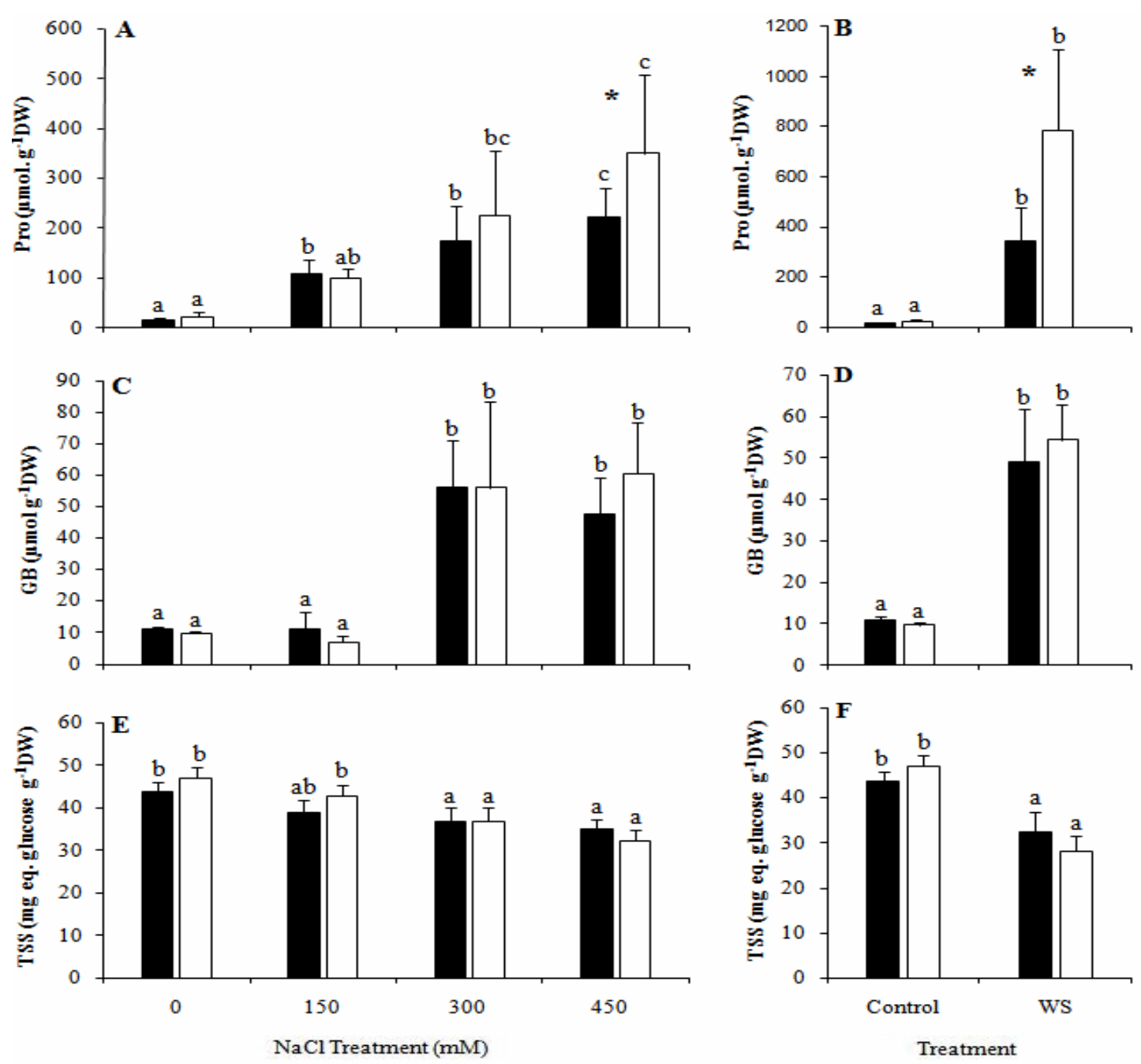

Fig. 4. Proline (Pro, $\mu$ mol per gram DW) (A, B), glycine betaine (GB, $\mu$ mol per gram DW) (C, D), and total soluble sugars (TSS, mg equivalent of glucose per gram DW) (E, F) in tomato leaves after 25 days (sampling 1, black bars) or 33 days (sampling 2, white bars) of salt (A, C, E) or water $(B, D, F)$ stress treatments (means $\pm S D, n=3$ ). Different lower case letters indicate significant differences between treatments, for the same sampling, according to Tukey test $(\alpha=0.05)$; asterisks indicate significant differences between sampling 1 and sampling 2 , for each treatment

the visual appearance of the plants, which were clearly wilted, but had not lost their green colour (data not shown).

\section{Proline content}

Application of salt treatments significantly increased Pro levels in tomato leaves, in a concentration-dependent manner. Mean Pro values in the presence of $300 \mathrm{mM}$ and $450 \mathrm{mM}$ external $\mathrm{NaCl}$ also increased with longer times of treatment although the differences observed between the two samplings of plant material were significant only at $450 \mathrm{mM} \mathrm{NaCl}$. Under the strongest salt stress conditions tested, Pro levels reached about $350 \mu \mathrm{mol}$ per gram DW, which represented an increase of 16fold with respect to the non-treated controls (Fig. 4A).

Pro accumulation was more clearly observed in plants kept without irrigation, with increases of about 20-fold and 36-fold after 25 and 33 days, respectively, of water stress (Fig. 4B). Pro contents in the plants subjected to the strongest water stress treatment (33 days without irrigation), in terms of dry weight (ca. $800 \mu \mathrm{mol} \mathrm{g}^{-1}$ ) were about double than those determined in plants treated for the same time with $450 \mathrm{mM} \mathrm{NaCl}$ (Figs. 4A and B); however, considering the drastic reduction of water content in non-irrigated plants, it can be said that both treatments induced Pro accumulation to similar levels, in absolute terms.

\section{Glycine betaine}

Salt and water stress also induced the synthesis and accumulation of GB in tomato (Figs. $4 \mathrm{C}$ and D). Yet the absolute values of $\mathrm{GB}$ content reached in plants watered with 300 or $450 \mathrm{mM} \mathrm{NaCl}(50-60 \mu \mathrm{mol}$ per gram DW) and its relative increase as compared to the control plants (ca. 5-fold) were lower than those of Pro. Moreover, no time-dependent increase in GB levels was detected in this experiment, as the values measured for the two samplings of plant material were not significantly different (Fig. 4C). The same results were obtained for plants subjected to 25 or 33 days of water stress (Fig. 4D).

\section{Totalsoluble sugars}

The total amount of soluble sugars slightly decreased in saltstressed plants, but significant differences were registered only 
starting with $300 \mathrm{mM} \mathrm{NaCl}$ in both samplings (Fig. 4E). Under water stress conditions the decrease was also significant and more accentuated after a longer drought treatment (Fig. 4F).

\section{Malondialdehyde}

MDA is a product of membrane lipid peroxidation and, as mentioned above, is considered a reliable marker of oxidative stress; thus, higher MDA contents should correspond to a higher degree of oxidative stress. As expected, MDA levels increased with all treatments, mostly after longer exposure to stress, so higher values were registered in the second sampling, after 33 days of treatment (Tables 2 and 3). The most affected plants by oxidative stress were those treated with $450 \mathrm{mM} \mathrm{NaCl}$, in which the highest MDA contents were measured (Table 2).

Table 3. Effects of drought stress on MDA and non-enzymatic antioxidant levels in plants after 25 days (sampling 1) and 33 days (sampling 2) of treatment

\begin{tabular}{|c|c|c|c|}
\hline \multirow{2}{*}{ Parameters } & \multirow{2}{*}{ Sampling } & \multicolumn{2}{|c|}{ Treatments } \\
\hline & & Control & Water stress \\
\hline MDA & 1 & $145.07 \pm 13.00 \mathrm{a}$ & $173.18 \pm 5.20 b$ \\
\hline$\left(n m o l g^{-1} \mathrm{DW}\right)$ & 2 & $149.30 \pm 7.00 \mathrm{a}$ & $198.35 \pm 7.60 b$ \\
\hline Total carotenoids & 1 & $648.02 \pm 31.00 b$ & $474.73 \pm 11.00 \mathrm{a}$ \\
\hline$\left(\mu g^{-1} \mathrm{DW}\right)$ & 2 & $659.53 \pm 36.00 b$ & $357.15 \pm 3.60 a$ \\
\hline Total phenolics & 1 & $9.71 \pm 0.17 \mathrm{a}$ & $12.10 \pm 1.90 \mathrm{~b}$ \\
\hline (mg eq. GA g $\left.{ }^{-1} \mathrm{DW}\right)$ & 2 & $12.41 \pm 0.60 \mathrm{a}$ & $19.48 \pm 0.90 b$ \\
\hline Total flavonoids & 1 & $10.19 \pm 0.30 \mathrm{~b}$ & $7.03 \pm 0.20 \mathrm{a}$ \\
\hline (mg eq. $\mathrm{C} \mathrm{g}^{-1} \mathrm{DW}$ ) & 2 & $8.74 \pm 0.60 b$ & $5.10 \pm 0.50 \mathrm{a}$ \\
\hline
\end{tabular}

$\overline{\text { Values shown are means followed by } \pm \overline{S D}(\mathrm{n}=5) \text {. Different }} \overline{\text { lower case letters in a }}$ file indicate significant differences between treatments, for each compound and sampling; Abbreviations: MDA, malondialdehyde; GA, gallic acid; C, catechin; DW, dry weight

\section{Total carotenoids, phenolics and flavonoids}

Carotenoid levels in leaves decreased in all treatments with respect to the control. In plants treated with $450 \mathrm{mM} \mathrm{NaCl}$ this reduction was of about $50 \%$. When comparing the two samplings, lower values were registered in plants exposed for a longer time to stress in all treatments (Tables 2 and 3). Contrary to the pattern of variation of carotenoids, total phenolics increased in plants under stress, especially in those treated with high salt concentrations. Values were significantly higher in plants from the second sampling than in those from the first one in all stress treatments (Tables 2 and 3 ). A different response to the type of stress was observed in total flavonoid contents, which increased significantly in the presence of $\mathrm{NaCl}$ (Table 2) but decreased under drought conditions (Table 3 ).

\section{Discussion}

All our major crops and most wild species are relatively sensitive to environmental stress conditions such as drought or salinity, but tomato is moderately resistant to salt,

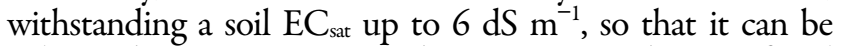
cultivated in regions exposed to a certain degree of soil salinisation (Maggio et al., 2004). Yet high soil salinity inhibits seed germination and plant growth, and causes reduction in crop yields (Dalton et al., 1997; Romero-Aranda et al., 2002). In this study, young tomato plants have been grown in the presence of increasing concentrations of $\mathrm{NaCl}$, and a concentration- and time- dependent inhibition of vegetative growth has been observed, which was better shown by the reduction of the fresh weight of the plants; this was not unexpected, since inhibition of growth is probably the most general response of plants to stress (Munns, 2002; Munns and Tester, 2008). Despite the fact that high salinity should cause cellular dehydration, in the experimental conditions used here the water content of the plants was reduced very slightly in the presence of salt, suggesting that tomato plants activate relatively efficient mechanisms to cope with the osmotic component of salt stress, and that growth inhibition is mostly due to the ionic toxicity of the salt. Water stress also inhibited growth but, contrary to salinity, in this case a severe dehydration of the plants was observed.

Another difference between salt and water stress treatments refers to changes in chlorophyll contents. In plants treated with high $\mathrm{NaCl}$ concentrations, a significant reduction in chlorophyll levels, up to ca. $40 \%$ of the non-treated controls, was observed. The decrease in chlorophyll levels in plants affected by salt is due to the inhibition of chlorophyll synthesis, together with the activation of its degradation by the enzyme chlorophyllase (Santos, 2004). Yet, reduction of chlorophyll contents is not the only reason for the inhibition of photosynthesis in the presence of salt, since $\mathrm{NaCl}$ also inhibits key enzymes involved in this process, such as Rubisco and PEP carboxylase (Soussi et al., 1998). Although water stress should also reduce chlorophyll levels and photosynthetic activity (Alberte et al. 1977; Mafakheri et al., 2010; Sanchez et al., 1983), this was not observed in the present study, probably because the time that the plants were maintained without irrigation was not long enough to detect these effects.

Proline is generally considered as a good indicator of environmental stress in tomato (Clausen, 2005) and there are many reports describing an increase in Pro contents as a response to water or salt stress in this species (Babu et al., 2012; Ghorbanli et al., 2013; Giannakoula and Ilias, 2013; Inal, 2002; Handa et al., 1986; Nahar and Gretzmacher, 2002; Umebese et al., 2009; Yokas et al., 2008), although it should be mentioned that data specific for cherry tomatoes are rather scarce (Maggio et al., 2007; Rosales et al., 2007). What is not so clear is the possible contribution of Pro accumulation to the (relative) resistance of tomato to salinity. When comparing tomato cultivars with differences in their degree of salt tolerance, in some cases the more tolerant cultivars were found to synthesise higher amounts of Pro under stress (Ali et al., 2011), but in others there was no correlation between tolerance and Pro levels (Alian et al., 2000). In the present study, a clear positive correlation between Pro accumulation and the intensity of the applied stress treatments has been established; that is, of Pro levels with the electric conductivity of the substrate - reflecting increasing $\mathrm{NaCl}$ concentrations in the nutritive solution - and with the time of exposure to stress. Moreover, Pro reached levels high enough to play a significant role in cellular osmotic adjustment under these stress conditions. Taken together, these data strongly support the notion that Pro is the major physiological osmolyte in cherry tomato, as it has been suggested for other tomato varieties (Nahar and Gretzmacher, 2002).

Usually, a given plant species accumulate preferentially a particular type of osmolyte in response to environmental stress; there have even been attempts to use this preference for one specific type of compatible solute as a taxonomic criterion in wild species (Gorham et al., 1980; Tipirdamaz et al., 2006). In agreement with this idea, and since Pro appears to be the major osmolyte in tomato, it is generally accepted that tomato does not accumulate glycine betaine in natural conditions; in fact, it has 
been reported that this species lacks two enzymes required for GB biosynthesis (Goel et al., 2011). Nevertheless, exogenous application of GB to tomato plants improves their resistance to drought (Rezaei et al., 2012) and salinity (Chen et al., 2009; Heuer, 2003; Makela et al., 1998). On the other hand, there are some examples of plant species that under severe stress conditions can activate the simultaneous synthesis of several osmolytes to help alleviate the detrimental effects of stress, by contributing to osmotic adjustment and/or acting as 'osmoprotectants', as it has been recently discussed (Tipirdamaz et al., 2006; Gil et al., 2013). This seems to be the case also for tomato, at least for the cherry variety: contrary to the general assumption, in the present study the accumulation of GB, in response to water or salt stress treatments, has been detected in tomato plants. It is true that the maximum levels of GB measured (ca. $50 \mu \mathrm{mol} \mathrm{g}^{-1} \mathrm{DW}$ ) were about 10-fold lower than those of Pro in the same plants - and also much lower than those measured in taxa that are clear GB accumulators (Boscaiu et al., 2011; Gil et al., 2014). Therefore, GB will have only a modest effect on osmotic balance in stressed tomato plants, but may still contribute significantly to stress resistance due to its putative functions as low-molecular-weight chaperon and/or ROS scavenger. Most published data support the absence of detectable GB in tomato; yet the present results are not the only evidence for accumulation of endogenous GB in response to stress, which has also been reported in plants submitted to chilling, where a threshold level ensures sufficient protection to low temperatures (Park et al., 2006).

The increase of sugars after mild salt and water stress is wellknown in tomato fruits, including the cherry variety, and moderate abiotic stress was even recommended as a strategy for improving the quality of tomatoes (Fernández-García et al., 2004; Sgherri et al., 2008; Ullah et al., 1994). Salt stress was found to produce an increase in carbohydrates accumulation, in the form of starch, in the early stages of fruit development, but as soluble sugars in ripe fruits, thus improving the flavour of tomatoes (Yin et al., 2010). There are also several reports of increased amount of sugars in tomato berries under drought (e.g. Nahar and Grezmacher, 2002). However, there are relatively few data published on stress-induced sugar accumulation in vegetative organs in this species, and they generally indicate a reduction of total carbohydrates in leaves (e.g. Amini and Ehsanpour, 2005; Li, 2009), as it has been found in the present study.

In addition to sugars, tomato fruits are rich in several compounds considered as 'health-promoting', such as carotenoids, flavonoids and other phenolics. These secondary metabolites play multiple roles in plants, including scavenging of ROS induced under different stress conditions and causing oxidative stress. A clear symptom of oxidative damage is cell membrane degradation; therefore, MDA - a product of membrane lipid peroxidation - is an excellent marker of oxidative stress (Del Rio et al., 1996). In this study a significant increase of MDA levels in tomato leaves upon salt and water stress treatments of the plants was obseved, in agreement with previous reports showing a salt-induced increase of MDA contents in tomato leaves (Shalata and Thal, 1998), roots (Shalata et al., 2001) and fruits (Rosales et al., 2006).

Mild and moderate saline and water stress produce also an increase in carotenoids levels in tomato fruits. Lycopen, the main carotenoid in tomato, is known as an important natural antioxidant with anti-carcinogenic properties (Krauss et al, 2006). In addition, lycopen is responsible for the red colour of tomatoes, aspect of great economic importance and therefore salt treatments are recommended as an alternative strategy to transgenic crops for obtaining tomatoes with higher amounts of carotenoids (Borghesi et al., 2011). In the present work, carotenoid levels were measured in tomato leaves (not fruits) and a reduction was detected under stress conditions; this is in agreement with previous reports that found a negative correlation between $\mathrm{Na}^{+}$and carotenoid contents in tomato leaves (Juan et al., 2005; Tuna et al., 2014).

Salt stress led to a significant increase of phenolics and flavonoids in leaves of plants submitted to the salt treatment and an enhancement of the former in water-stressed plants. There are many publications reporting an increase in the levels of phenolics and flavonoids in tomato fruits in conditions of abiotic stress, which is a topic of direct interest for human health (e.g. Krauss $e t$ al., 2006; Ali and Ismail, 2014); in fact, consumption of tomatoes has been recommended to reduce the risk of cardiovascular diseases and cancer (Holiman et al., 1996). Similar studies on leaf material are much scarcer; for example, SánchezRodriguez et al. (2011) found an enhancement of some phenolics and flavonoids under moderate water stress (50\% of the field capacity) in the more tolerant cultivars of cherry tomatoes, but a reduction in the more sensitive ones, in partial agreement with the data presented here.

\section{Conclusions}

Salt and water stress treatments inhibited vegetative growth in cherry tomato, a variety that has not been extensively studied yet, despite its growing commercial interest. In non-irrigated plants, a strong dehydration was partly responsible for reduction of leaf fresh weight, an effect not detected in the presence of $\mathrm{NaCl}$. Both stresses led to the accumulation in the leaves of high levels of Pro, which function as the major osmolyte in cherry tomato, responsible for osmotic adjustment under stress conditions. Glycine betaine also accumulated as a response to salt and water stress - albeit at lower levels than Pro - despite numerous publications reporting its absence in tomato plants; therefore, GB appears to act as a secondary osmolyte that could contribute to stress tolerance in cherry tomato. Both stress treatments caused secondary oxidative stress in the plants, as indicated by a significant increase in malondialdehyde (MDA) contents. The increase in antioxidant phenolic compounds levels in leaves can be considered as part of the response induced to cope with oxidative stress. Contrary to what has been reported for tomato fruits, other metabolites such as total soluble sugars or carotenoids do not increase, but rather decrease in leaves in response to the stress treatments.

\section{References}

Aghaleh M, Niknam V, Ebrahimzadeh H, Razavi K (2009). Salt stress effects on growth, pigments, proteins and lipid peroxidation in Salicornia persica and S. europaea. Biol Plant 53:243-248.

Alberte RS, Thornber JP, Fiscus EL (1977). Water stress effects on 
the content and organization of chlorophyll in mesophyll and bundle sheath chloroplasts of maize. Plant Physiol 59:351-353.

Ali HEM, Ismail GSM (2014). Tomato fruit quality as influenced by salinity and nitric oxide. Turk J Bot 38:122-129.

Ali SG, Rab A, Khan UA, Nawab K (2011). Enhanced proline synthesis may determine resistance to salt stress in tomato cultivars. PakJ Bot 43:2707-2710.

Alian A, Altman A, Heuer B (2000). Genotypic differences in salinity and water stress resistance tolerance of fresh market tomatoes. Plant Sci 152:59-65.

Amini F, Ehsanpour AA (2005). Soluble proteins, proline, carbohydrates and $\mathrm{Na}^{+} / \mathrm{K}^{+}$changes in two tomato (Lycopersicon esculentum Mill.) cultivars under in vitro salt stress. Am J Biochem Biotechnol 1:204-208.

Appel K, Hirt H (2004). Reactive oxygen species: metabolism, oxidative stress, and signal transduction. Annu Rev Plant Biol 55:373-399.

Ashraf MY, Foolad MR (2007). Roles of glycine betaine and proline in improving plant abiotic stress resistance. Environ Exp Bot 59:206-216.

Babu MA, Singh D, Gothandam KM (2012). The effect of salinity on growth, hormones and mineral elements in leaf and fruit of tomato cultivars PKM1.J Anim PI Sci 22:159-164.

Bates LS, Waldren RP, Tear LD (1973). Rapid determination of free proline for water-stress studies. Plant Soil 39:205-207.

Blainski A, Lopes GC, de Mello JCP (2013). Application and analysis of the Folin Ciocalteu method for the determination of the total phenolic content from Limonium brasiliense $\mathrm{L}$. Molecules 18:6852-6865.

Borghesi E, González-Miret L, Escudero-Gilete ML, Malorgio F, Heredia FJ, Meléndez-Martínez AJ (2011). Effects of salinity stress on carotenoids, anthocyanins and color of diverse tomato genotypes. J Agric Food Chem 59:11676-11682.

Boscaiu M, Tifrea A, Donat P, Mayoral O, Llinares J, Bautista I, Lidón A, Lull C, Vicente O (2011). Seasonal variation of glycine betaine in plants from a littoral salt - marsh in SE Spain. Bull UASVM Horticulture 68:543-544.

Büssis D, Heineke D (1998). Acclimation of potato plants to polyethylene glycol-induced water deficit II. Contents and subcellular distribution of organic solutes. J Exp Bot 49:13611370.

Chen S, Gollop N, Heuer B (2009). Proteomic analysis of saltstressed tomato (Solanum lycopersicum) seedlings: effect of genotype and exogenous application of glycinebetaine. J Exp Bot 60:2005-2019.

Chen THH, Murata N (2008). Glycinebetaine: an effective protectant against abiotic stress in plants. Trends Plant Sci 13:499-505.

Cheynier V, Comte G, Davies KM, Lattanzio V, Martens S (2013). Plant phenolics: recent advances on their biosynthesis, genetics, and ecophysiology. Plant Physiol Biochem 72:1-20.

Clausen W (2005). Proline as a measure of stress in tomato plants. Plant Sci 168:241-248.
Cuartero J, Fernández Muñoz J (1999). Tomato and salinity. Sci Hort 78:83-125.

Dalton FN, Maggio A, Piccinni G (1997). Effect of root temperature on plant response functions for tomato: comparison of static and dynamic salinity stress indices. Plant Soil 192:307-319.

Del Rio D, Stewart AJ, Pellegrini N (2005). A review of recent studies on malondialdehyde as toxic molecule and biological marker of oxidative stress. Nutr Metab Cardiovas 15: 316-328.

Di Ferdinando M, Brunetti C, Fini A, Tattini M (2012). Flavonoids as antioxidants in plants under abiotic stresses. In: Ahmad P, Prasad MNV (Eds). Abiotic stress responses in plants: metabolism, productivity and sustainability. Springer, New York pp. 159-179.

Dubois M, Gilles KA, Hamilton JK, Reberd PA, Smith F (1956). Colorimetric method for determination of sugars and related substances. Anal Chem 28:350-356.

Fernández-García N, Martínez V, Cerda A, Carvajal M (2004). Fruit quality of grafted tomato plants grown under saline conditions. J Hort Sci Biotech 79:995-1001.

Gavaghan CL, Li JV, Hadfield ST, Hole S, Nicholson JK, Wilson ID, Howe PWA, Stanley PD, Holmes E (2011). Application of NMR-based metabolomics to the investigation of salt stress in maize (Zea mays). Phytochem Anal 22:214-224.

Ghorbanli M, Gafarabad M, Amirkian T, Mamaghani BA (2013). Investigation on proline, total protein, chlorophyll ascorbate and dehydroascorbate changes under drought stress in Akria and Mobil tomato cultivars. Iran J Plant Physiol 3:651-658.

Giannakoula AE, Ilias IF (2013). The effect of water stress and salinity on growth and physiology of tomato. Arch Biol Sci Belgrade 65:611-620.

Gil R, Bautista I, Boscaiu M, Lidón A, Wankhade S, Sánchez H, Llinares J, Vicente O. (2014). Responses of five Mediterranean halophytes to seasonal changes in environmental conditions. AoB Plants, doi:10.1093/aobpla/plu049.

Gil R, Boscaiu M, Lull C, Bautista I, Lidón A, Vicente O (2013). Are soluble carbohydrates ecologically relevant for salt tolerance in halophytes? Funct Plant Biol 40:805-818.

Gill SS, Tuteja N (2010). Reactive oxygen species and antioxidant machinery in abiotic stress tolerance in crop plants. Plant Physiol Biochem 48:909-930.

Goel D, Singh AK, Yadav V, Babbar SB, Murata N, Bansal KC (2011). Transformation of tomato with a bacterial codA gene enhances tolerance to salt and water stresses. J Plant Physiol 168:1286-1294.

Gorham J, Hughes LL, Wyn Jones RG (1980). Chemical composition of salt-marsh plants from Ynys Môn (Anglesey): the concept of physiotypes. Plant Cell Environ 3:309-318.

Gould KS, Lister C (2006). Flavonoid function in plants. In: Andersen ØM, Marham KR (Eds). Flavonoids, chemistry, biochemistry and application, CRC Press, Boca Raton pp $397-$ 442.

Grieve CM, Grattan SR (1983). Rapid assay for determination of water soluble quaternary ammonium compounds. Plant Soil 
10

70:303-307.

Gummuluru S, Hobbs SLA, Jana S (1989). Physiological responses of drought tolerant and drought susceptible durum wheat genotypes. Photo Synthetica 23:479-485.

Handa S, Handa AK, Hasegawa PP, Bressan RA (1986). Proline accumulation and the adaptation of cultured plant cells to water stress. Plant Physiol 80:938-945.

Hare PD, Cress WA, Van Staden J (1998). Dissecting the roles of osmolyte accumulation during stress. Plant Cell Environ 21:535-553.

Heuer B (2003). Influence of exogenous application of proline and glycinebetaine on growth of salt-stressed tomato plants. Plant Sci 165:693-699.

Hodges DM, De Long JM, Forney CF, Robert K, Prange RK (1999). Improving the thiobarbituric acid-reactive-substances assay for estimating lipid peroxidation in plant tissues containing anthocyanin and other interfering compounds. Planta 207:604-611.

Holiman PCH, Hertog MGL, Katan MB (1996). Analysis and health effects of flavonoids. Food Chem 57:43-46.

Inal A (2002). Growth, proline accumulation and ionic relations of tomato (Lycopersicon esculentum $\mathrm{L}$.) as influenced by $\mathrm{NaCl}$ and $\mathrm{Na}_{2} \mathrm{SO}_{4}$ salinity. Turk J Bot 26:285-290.

Juan M, Rivero RM, Romero L, Ruiz JM (2005). Evaluation of some nutritional and biochemical indicators in selecting saltresistant tomato cultivars. Environ Exp Bot 54:193-201.

Krauss S, Schniztler WH, Grassmann J, Woitke M (2006). The influence of different electrical conductivity values in a simplified recirculating soilless system on inner and outer fruit quality characteristics of tomato. J Agric Food Chem 54:441448.

Li G, Wan SW, Zhou J, Yang ZY, Qin P (2010). Leaf chlorophyll fluorescence, hyperspectral reflectance, pigments content, malondialdehyde and proline accumulation responses of castor bean (Ricinus communis L.) seedlings to salt stress levels. Ind Crop Prod 31:13-19.

Li Y (2009). Phsiological responses of tomato seedlings (Lycopersicon esculentum) to salt stress. Mod Appl Sci 3:171-176.

Mafakheri A, Siosemardeh A, Bahramnejad B, Struik PC, Sohrabi Y (2010). Effect of drought stress on yield, proline and chlorophyll contents in three chickpea cultivars. Aust J Crop Sci 4:580-585.

Maggio A, De Pascale S, Angelino G, Ruggiero C, Barbieri G (2004). Physiological responses of tomato to saline irrigation in long-term salinized soils. Eur J Agron 21:149-159.

Maggio A, Raimondi G, Martini A, De Pascale S (2007). Salt responses in tomato beyond the salinity tolerance threshold. Env Exp Bot 59:276-282.

Makela P, Jokinen K, Kontturi M, Peltonen-Sainio P, Pehu E, Somersalo $S$ (1998). Foliar application of glycinebetaine novel product from sugar-beet as an approach to increase tomato yield. Ind Crop Prod 7:139-148.

Munns R (2002). Comparative physiology of salt and water stress. Plant Cell Environ 25:239-250.
Munns R, Tester M (2008). Mechanisms of salinity tolerance. Annu Rev Plant Biol 9:651-681.

Nahar K, Gretzmacher R (2002). Effect of water stress on nutrient uptake, yield and quality of tomato (Lycopersicon esculetum Mill.) under subtropical conditions. Bodenkultur 53:45-51.

Nawaz K, Ashraf M (2010). Exogenous application of glycinebetaine modulates activities of antioxidants in maize plants subjected to salt stress. J Agron Crop Sci 196:28-37.

Parida A, Das AB, Das P (2002). NaCl stress causes changes in photosynthetic pigments, proteins and other metabolic components in the leaves of a true mangrove, Bruguiera parviflora, in hydroponic cultures. J Plant Biol 45:28-36.

Parida A, Das AB, Sanada Y, Mohanty P (2004). Effects of salinity on biochemical components of the mangrove Aegiceras corniculatum. Aquat Bot 80:77-87.

Parida AK, Das AB (2005). Salt tolerance and salinity effect on plants: a review. Ecotoxic Environ Safe 603:324-349.

Park EJ, Jeknic Z, Chen THH (2006). Exogenous application of glycinebetaine increases chilling tolerance in tomato plants. Plant Cell Physiol 47:706-714.

Parvaiz A, Satyawati S (2008). Salt stress and phyto-biochemical responses of plants: a review. Plant Soil Environ 53:89-99.

Pollastri S, Tattini M (2011). Flavonols: old compounds for old roles. Ann Bot 108:1225-1233.

Rezaei MA, Jokar J, Ghorbanli M, Kaviani B, Kharabian-Masouleh A (2012). Morpho-physiological improving effects of exogenous glycine betaine on tomato (Lycopersicum esculentum Mill.) cv. PS under drought stress conditions. Plant Omics 5:79-86.

Romero-Aranda R, Soria T, Cuartero JJ (2002). Greenhouse mist improves yield of tomato plants grown under saline conditions. J Am Soc Hortic Sci 127:644-648.

Rosales MA, Rios JJ, Castellano R, López-Carrión AI, Romero L, Ruiz JM (2007). Proline metabolism in cherry tomato exocarp in relation to temperature and solar radiation. J Hort Sci Biotech 82:739-744.

Rosales MA, Ruiz JM, Hernández J, Soriano T, Castilla N, Romero L (2006). Antioxidant content and ascorbate metabolism in cherry tomato exocarp in relation to temperature and solar radiation. J Sci Food Agric 86:1545-1551.

Sanchez RA, Hall AJ, Trapani N, Cohen de Hunau R (1983). Effects of water stress on the chlorophyll content, nitrogen level and photosynthesis of leaves of two maize genotypes. Photosynth Res 4:35-47.

Sánchez-Rodríguez E, Moreno DA, Ferreres F, Rubio-Wilhelmi MM, Ruiz JM (2011). Differential responses of five cherry tomato varieties to water stress: Changes on phenolic metabolites and related enzymes. Phytochemistry 72:723-729.

Santos CV (2004). Regulation of chlorophyll biosynthesis and degradation by salt stress in sunflower leaves. Sci Hort 103:9399.

Sgherri C, Kadlecová Z, Pardossi A, Navari-Izzo F, Izzo R (2008). Irrigation with diluted seawater improves the nutritional value of cherry tomatoes. J Agri Food Chem 56:3391-3397. 
Shalata A, Mittova V, Volokita M, Guy M, Tal M (2001). Responses of the cultivated tomato and its wild-tolerant relative Lycopersicon pennellii to salt-dependent oxidative stress: The root antioxidative system. Physiol Plant 112:487-494.

Shalata A, Tal M (1998). The effect of salt stress on lipid peroxidation and antioxidants in the leaf of the cultivated tomato and its wild salt-tolerant relative Lycopersicon pennellii. Physiol Plant 104:169-174.

Sims DA, Gamon JA (2002). Relationships between leaf pigment content and spectral reflectance across a wide range of species, leaf structures and developmental stages. Remote Sens Environ 81:337-354.

Slimestad R, Fossen T, Verheul TJ (2008). The flavonoids of tomatoes. J Agric Food Chem 56:2436-2441.

Soussi M, Ocaña A, Lluch C (1998). Effect of salt stress on growth, photosynthesis and nitrogen fixation in chick-pea (Cicer arietinum L.) cultivars. J Exp Bot 49:1339-1347.

Stewart GR, Lee JA (1974). The role of proline accumulation in halophytes. Planta 120:279-289.

Szabados L, Savouré A (2010). Proline: a multifunctional amino acid. Trends Plant Sci 15:89-97.

Tipirdamaz R, Gagneul D, Duhaze C, Ainouche A, Monnier C, Ozkum D, Larher F (2006). Clustering of halophytes from an inland salt marsh in Turkey according to their ability to accumulate sodium and nitrogenous osmolytes. Environ Exp Bot 57:139-153.

Treutter D (2005). Significance of flavonoids in plant resistance and enhancement of their biosynthesis. Plant Biol 581-591.

Treutter D (2006). Significance of flavonoids in plant resistance: a review. Environ Chem Lett 4:147-157.

Tuna AT (2014). Influence of foliarly applied different triazole compounds on growth, nutrition, and antioxidant enzyme activities in tomato (Solanum lycopersicum L.) under salt stress. Austral J Crop Sci 8:71-79.

Tyree MT, Jarvis PG (1982). Water in tissue and cells. In: Lange OL, Nobel PS, Osmond OB, Ziegler M (Eds). Encyclopedia of Plant Physiology Vol 2. Springer, Berlin pp 35-77.
Ullah SM, Gerzabeck MH, Sonja G (1994). Effect of seawater and soil-salinity on ion uptake, yield and quality of tomato (fruit). Bodenkultur 45:227-237.

Umebese CE, Olatimilehin TO, Ogunsusi TA (2009). Salicylic acid protects nitrate reductase activity, growth and proline in amaranth and tomato plants during water deficit. Am J Agric Biol Sci 4:224-229.

Van Breusegem F, Dat JF (2006). Reactive oxygen species in plant cell death. Plant Physiol 141:384-390.

Verbruggen N, Hermans C (2008). Proline accumulation in plants: a review. Amino Acids 35:753-759.

Vicente O, Boscaiu M, Naranjo MA, Estrelles E, Belles JM, Soriano P (2004). Responses to salt stress in the halophyte Plantago crassifolia (Plantaginaceae). J Arid Environ 58:463-481.

Winkel-Shirley B (2002). Biosynthesis of flavonoids and effect of stress. Curr Opin Plant Biol 5:218-223.

Wiseman H (2006). Isoflavonoids and human health. In: Andersen ØM, Marham KR (Eds). Flavonoids, chemistry, biochemistry and application. CRC Press, Boca Raton pp 397-442.

Yin Y-G, Kobayashi Y, SanukiA, Kondo S, Fukuda N, Ezura H, Sugaya S, Matsukura C (2010). Salinity induces carbohydrate accumulation and sugar-regulated starch biosynthetic genes in tomato (Solanum lycopersicum L. cv. 'Micro-Tom') fruits in an $\mathrm{ABA}$ and osmotic stress-independent manner. J Exp Bot 61:563-574.

Yokaş I, Tuna AL, Bürün B, Altunlub H, Altan F, Kaya C (2008). Responses of the tomato (Lycopersicon esculentum Mill.) plants to exposure to different salt forms and rates. Turk J Agric For 32:319-329.

Zhishen J, Mengcheng T, Jianming W (1999). The determination of flavonoid contents in mulberry and their scavenging effects on superoxide radicals. Food Chem 64:555-559. 